\title{
Three Dendromonocotyle species (Monogenea: Monocotylidae) reported from captive rays, including $D$. lotteri sp. n. from Himantura gerrardi (Elasmobranchii: Dasyatidae) in the public aquarium at the Atlantis resort, Dubai
}

\author{
David B. Vaughan ${ }^{1}$ and Leslie A. Chisholm ${ }^{2}$ \\ ${ }^{1}$ Aquatic Animal Health Research, Two Oceans Aquarium, P.O. Box 50603, Victoria and Alfred Waterfront, Cape Town, 8000, \\ South Africa; \\ ${ }^{2}$ Monogenean Research Laboratory, Parasitology Section, The South Australian Museum, North Terrace, Adelaide, South Australia \\ 5000, Australia
}

\begin{abstract}
Dendromonocotyle lotteri sp. n. is described from the dorsal skin surface of the stingray Himantura gerrardi (Gray) on exhibit in the public aquarium at the Atlantis resort in Dubai. It is differentiated from all other Dendromonocotyle species by the unique morphology of the distal portion of the sclerotised male copulatory organ. Dendromonocotyle lotteri is the second representative in the genus with 56 marginal haptoral papillae having a papillae to loculus association represented numerically as 6-6-8-8. We found Dendromonocotyle colorni Chisholm, Whittington et Kearn, 2001 on the same host specimens at the Atlantis resort public aquarium and Dendromonocotyle kuhlii Young, 1967 on Neotrygon kuhlii (Müller et Henle) kept at Burgers' Zoo Aquarium in Arnhem, The Netherlands. Supplemental information is provided for both $D$. colorni and $D$. kuhlii. The presence of Dendromonocotyle infections in public aquaria and host specificity are discussed. A key to the 17 species of Dendromonocotyle is also provided.
\end{abstract}

Key words: Monogenea, Monocotylidae, Dendromonocotyle, public aquarium, Himantura gerrardi, Neotrygon kuhlii, Dubai

Members of Dendromonocotyle Hargis, 1955 (Monogenea: Monocotylidae) have been reported on the dorsal surface of stingrays from the Dasyatidae, Myliobatidae and Urolophidae. There are currently 16 known species of Dendromonocotyle, of which 7 are reported from stingrays in captivity (see Chisholm and Whittington 1995, 2009, Chisholm et al. 2001, 2004, Vaughan et al. 2008). It has become clear that Dendromonocotyle infections can cause health problems in stingrays kept in public aquaria. Monogeneans are generally considered to be host specific but increasing data indicate that some Dendromonocotyle species can infect more than one host stingray species. This is cause for concern in public aquaria where multispecies elasmobranch displays are common.

The public aquarium at the Atlantis resort in Dubai is one of the newest international public aquaria, opening its doors to the public in September 2008. We recently received specimens from a monogenean outbreak on four Himantura gerrardi (Gray) specimens housed at the new aquarium and describe them here as a new species of Dendromonocotyle. We also give supplemental data for Dendromonocotyle colorni Chisholm, Whittington et Kearn, 2001 which was present on the same host stingrays. Ad- ditional data are provided for Dendromonocotyle kuhlii Young, 1967 found on the dorsal skin surface of Neotrygon kuhlii (Müller et Henle) at Burgers' Zoo Aquarium in Arnhem, The Netherlands.

\section{MATERIALS AND METHODS}

Four Himantura gerrardi, identified using Compagno (2003), were collected in the Arabian Gulf and kept on display at the public aquarium at the Atlantis resort, Dubai. The stingrays exhibited signs of monogenean infections and were removed to the quarantine facility for closer inspection. Numerous monogeneans were noted on the dorsal skin surface. The rays were given a freshwater bath for $1.5 \mathrm{~min}$ to give them immediate relief from the infection. All monogeneans collected after the freshwater bath were transferred directly to $70 \%$ ethanol and shipped to the senior author for identification. Dendromonocotyle kuhlii specimens collected from $N$. kuhlii at Burgers' Zoo Aquarium were fixed in $70 \%$ ethanol and sent to the senior author for species confirmation in March 2008. Upon arrival, monogeneans were re-hydrated in freshwater, stained in Alum Carmine, dehydrated in a graded ethanol series, cleared in cedarwood oil and mounted permanently in Canada balsam on glass microscope slides. Hamuli and marginal hooklets of some specimens were examined after total digestion of surrounding soft tissue using the modified 
proteolytic digestion technique of Harris et al. (1999) as used by Vaughan et al. (2008).

Mounted specimens were examined using an Olympus SZ60 Stereo Zoom dissection microscope fitted with an eyepiece micrometer and an Olympus CX41 compound light microscope fitted with phase-contrast and dark-field condensers. Drawings were made with the aid of a drawing tube. Measurements, given in micrometres as the mean \pm standard deviation followed in parentheses by the range and number measured, were taken using Olympus AnalySIS $5^{\circledR}$ software and Altra20 digital microscope camera except for total body length and width measurements of D. colorni which were calculated using an eyepiece micrometer on the dissecting microscope. Any curved male copulatory organs were measured using the poly-line function of the software, measuring their true lengths following the curvature.

Taxonomic terminology follows that of Chisholm et al. (2001). The type series of the new species and the voucher material of D. colorni are deposited in the Iziko South African Museum (SAMCTA) in Cape Town, 8000, South Africa, and the Australian Helminthological Collection (AHC) at the South Australian Museum, North Terrace, Adelaide, South Australia 5000 , Australia. Two voucher specimens of $D$. kuhlii are deposited in SAMCTA.

\section{RESULTS}

Monocotylidae Taschenberg, 1879

Dendromonocotyle Hargis, 1955

\section{Dendromonocotyle lotteri sp. $\mathrm{n}$.}

Figs. 1-4

Description. Based on 5 flattened adult specimens. Total body (Fig. 1) $3052 \pm 442.3(2720-3680, \mathrm{n}=5)$ long. Body proper $2693 \pm 422.7(2233-3167, \mathrm{n}=5)$ long and $2128 \pm 349.0 \quad(1800-2567, \mathrm{n}=5)$ maximum width at level of testis. Haptor $1379 \pm 230.1(1187-1681, n=5)$ in diameter, divided into 8 peripheral and 1 central loculus (Fig. 1). Haptoral rim consisting of 56 marginal papillae armed with 4-5 papillary sclerites (Figs. 1, 2A, ps). Terminal papillary sclerite as illustrated (Fig. 2A, tps). Marginal papillae to loculus associations as follows: posterior and postero-lateral loculi associated with 8 marginal papillae each; antero-lateral and anterior loculi associated with 6 loculi each. Tripartite sclerites (Fig. 2A, tri) observed at junction of radial septa and inner and outer-ring septa in some, but not all specimens (Fig. 1). Radial and inner ring septal sclerites uniform (Fig. 2A, ss). Outer ring sclerites as illustrated (Fig. 2A, os). Hamuli present, $88 \pm 2.0(86-90, n=3)$ long (Figs. 1, 2B). Fourteen marginal hooklets (Fig. 2C) $13 \pm 0.6(12-14, \mathrm{n}=8)$ long, distributed symmetrically in marginal valve between every 4 papillae (Fig. 1). Mouth ventral, subterminal. Subterminal groove anterior to mouth. Six pairs of antero-lateral gland openings anterior to, and on either side of mouth (Fig. 1); type of secretion they contain could not be determined. Pharynx $372 \pm 43.4(336-420, \mathrm{n}=5)$ long, $289 \pm 30.1$ $(262-328, n=5)$ wide. Eyespots not observed, possibly obscured by pigmentation of intestinal caecum. Intestinal caeca highly dendritic and heavily pigmented; extending from head to posterior portion of body proper (Fig. 1).

Ovary bi-lobed with branch looping right intestinal caecum before terminating at base of oötype (Figs. 1, 3A). Mehlis' gland present. Oötype $391 \pm 33.7$ (362-428, $\mathrm{n}=3$ ) long (Figs. 1, 3A). Tetrahedral egg (in distal portion of oötype) side length, $96 \pm 2.4(94-98, \mathrm{n}=2)$; short appendage present at one pole (Fig. 4A). Vaginal pore ventral, inconspicuous, positioned left of anterior-most part of ejaculatory bulb. Vagina $734 \pm 44.7(671-776, n=4)$ long, widens proximally, containing 2 spherical structures before terminating in a muscular arrowhead-shaped base (Figs. 1, 3A). Transverse vitelline duct anterior to ovary, passing over base of oötype or posterior to it (Figs. 1, 3A). Seminal receptacle not seen, possibly obscured by pigmented branches of intestinal caecum. Vitellarium concealed between pigmented branches of intestinal caeca. No spermatophores observed.

Testis single (Fig. 1), $271 \pm 25.4(237-297, \mathrm{n}=5)$ long, $526 \pm 73.1(444-612, \mathrm{n}=5)$ wide. Vas deferens originates from left side of testis, obscured by intestinal caecum, travels anteriorly, dorsal to vagina and anterodorsally to ejaculatory bulb before inflating to form seminal vesicle (Figs. 1, 3B). Seminal vesicle then narrows and enters ejaculatory bulb posteriorly. Ejaculatory bulb $353 \pm 28.4(334-400, \mathrm{n}=5)$ in diameter. Male copulatory organ (Figs. 1, 3B) $1126 \pm 45.7(1073-1192, \mathrm{n}=5)$ long, $15 \pm 0.4(14-15, \mathrm{n}=5)$ wide; extends to level of posterior portion of ovary. Distal portion of male copulatory organ with weak corresponding s-curve bends and spiral sclerotised filament (Figs. 3B, 4B). Distal tip cone-shaped, tapering to a point. Entire length of male copulatory organ surrounded by muscular sheath $105 \pm 26.2$ (69-126, $\mathrm{n}=5$ ) wide.

Type host: Himantura gerrardi (Gray), Dasyatidae.

Type locality: Atlantis resort public aquarium, Dubai.

Site on host: Dorsal skin surface.

Material deposited: SAMCTA 29469 (holotype and 2 paratypes), AHC 29678 and 29679 (2 paratypes).

Etymology: This species is named after Mr. Paul Lötter,

Director of Large Exhibits, Atlantis resort public aquarium,

Dubai, who collected the original material.

Remarks. The distal portion of the male copulatory organ is distinct following a series of corresponding weak s-curves and is surrounded by a sclerotised spiral filament, before tapering into a cone-like terminal section. This unique morphology distinguishes $D$. lotteri from all other Dendromonocotyle species. Dendromonocotyle lotteri is the second species together with $D$. colorni in the group with 56 marginal papillae with a papillae to loculus association represented numerically as 6-6-8-8 (Vaughan et al. 2008). All other Dendromonocotyle species with 56 marginal papillae conform to the papillae to loculus association represented numerically as 6-7-7-8 (Vaughan et al. 2008). 


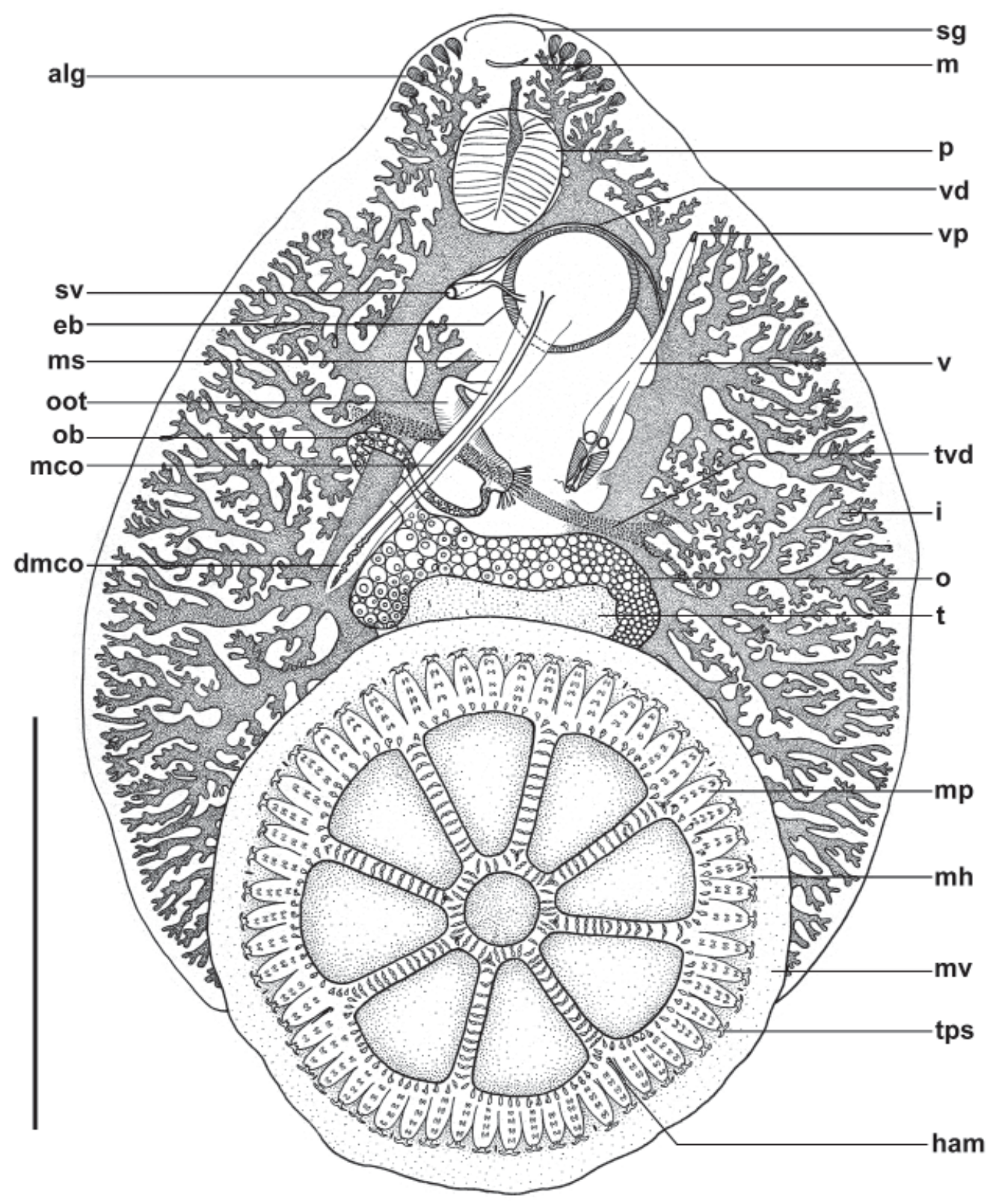

Fig. 1. Dendromonocotyle lotteri sp. n. Ventral view composite. Abbreviations: alg - antero-lateral gland duct openings; dmco - distal portion of male copulatory organ; eb - ejaculatory bulb; ham - hamulus; $\mathrm{i}$ - intestinal caecum; $\mathrm{m}$ - mouth; mco - male copulatory organ; $\mathrm{mh}$ - marginal hooklet; $\mathrm{mp}$ - marginal papilla; $\mathrm{ms}$ - muscular sheath surrounding male copulatory organ; $\mathrm{mv}-$ marginal valve; o - ovary; ob - ovarian branch; oot - oötype; $\mathrm{p}$ - pharynx; sg - subterminal groove; sv - seminal vesicle; $\mathrm{t}$ - testis; tps - terminal papillary sclerite; tvd - transverse vitelline duct; $v$ - vagina; vd - vas deferens; $v p-$ vaginal pore. Scale bar $=1000 \mu \mathrm{m}$.

\section{Dendromonocotyle colorni Chisholm, Whittington} et Kearn, 2001

Type host: Himantura uarnak (Forsskål), Dasyatidae. Additional host: Himantura gerrardi (Gray), Dasyatidae.

Type locality: Eilat Underwater Observatory, Israel. Additional localities: Sea World at uShaka Marine World, Durban, South Africa (Vaughan et al. 2008); Atlantis resort public aquarium, Dubai (present study).
Site on host: Dorsal skin surface.

Material deposited: SAMCTA 29473 (10 vouchers), AHC 29680 (5 vouchers).

Remarks. Fifteen flattened adult worms were examined from specimens of $H$. gerrardi from Atlantis resort, Dubai. These specimens conform morphologically in most aspects to those of the original description of Chisholm et al. (2001) and the redescription of Vaughan et al. (2008). However, they are the largest representatives 

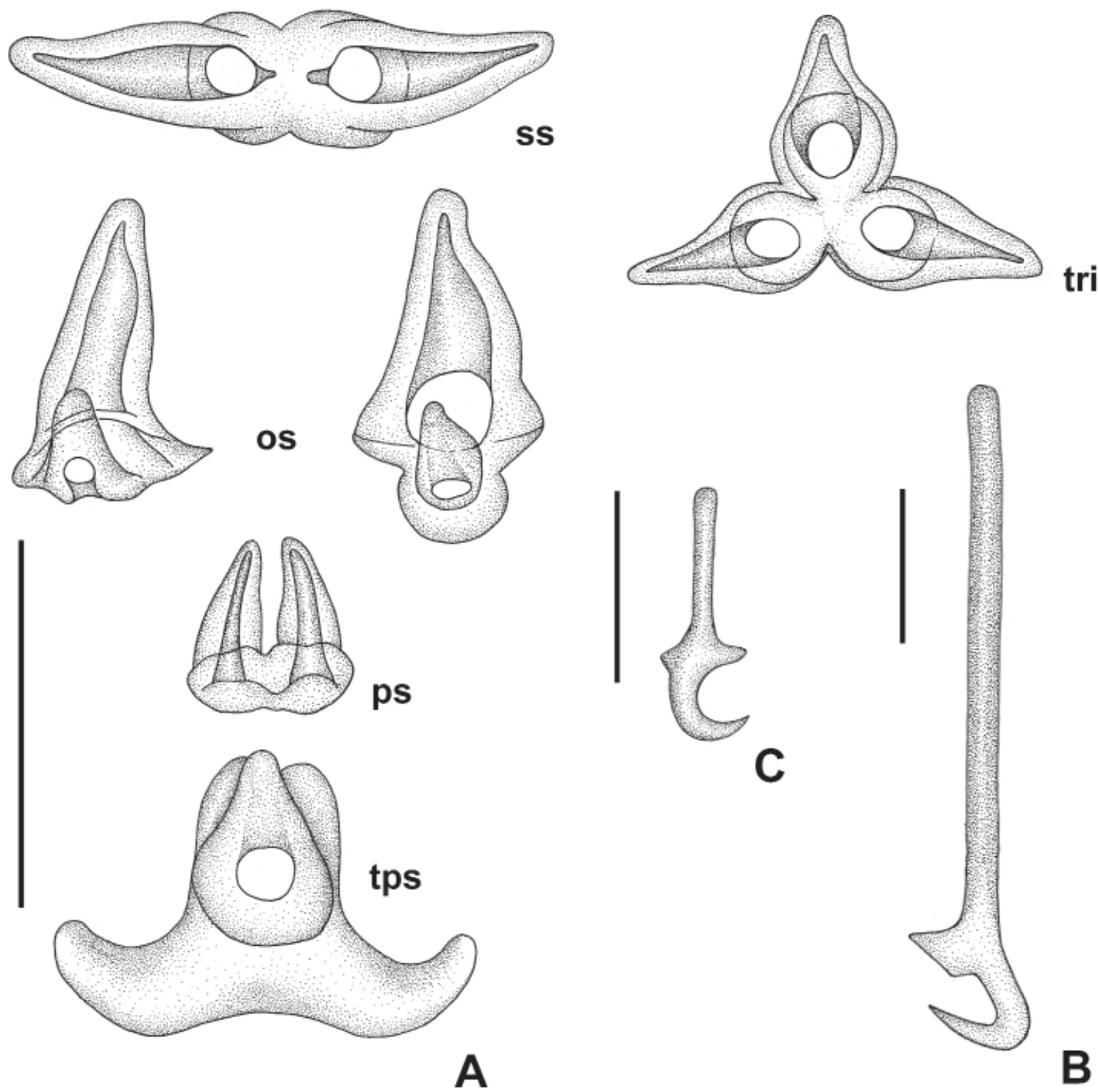

A

Fig. 2. Dendromonocotyle lotteri sp. n. Haptoral armature. A-papillary sclerites (ps), terminal papillary sclerite (tps) and radial and inner-ring septal sclerite (ss) including variations of outer-ring septal sclerites (os), and tripartite sclerite (tri) at the junction of inner and outer ring and radial septa; B - hamulus; $\mathbf{C}$ - marginal hooklet. Scale bars: A $=30 \mu \mathrm{m} ; \mathrm{B}=20 \mu \mathrm{m} ; \mathrm{C}=10 \mu \mathrm{m}$.

of the species collected to date with the total body length $4504 \pm 1103.6(3000-6200, \mathrm{n}=12)$ and the maximum width at the level of the testis $3569 \pm 1130.3(1720-5067$, $\mathrm{n}=15)$. The vas deferens passes anterior to the ejaculatory bulb before swelling to form the seminal vesicle in both the new voucher specimens and in the specimens described by Chisholm et al. (2001). In the material collected from $H$. gerrardi and $H$. uarnak from uShaka Marine World, Durban, South Africa, the vas deferens runs dorsally across the posterior section of the ejaculatory bulb (Vaughan et al. 2008). Tripartite sclerites are observed at the junctions of the radial septa and the inner and outerring septa in some voucher specimens, and the marginal papillae are armed with between 3-4 papillary sclerites, as seen in those from South Africa. This is the third report of $D$. colorni from stingrays in captivity and the second report from the Northern hemisphere.

\section{Dendromonocotyle kuhlii Young, 1967}

Supplemental information. Based on 2 flattened juvenile specimens. Haptoral rim consisting of 56 marginal papillae armed with 3 papillary sclerites. Marginal papillae to loculus association as follows: posterior loculi associated with 8 marginal papillae each, postero-lateral and antero-lateral loculi with 7 marginal papillae each and anterior loculi associated with 6 marginal papillae each. Fourteen marginal hooklets $10 \pm 0.9(10-11, \mathrm{n}=3)$ long, distributed symmetrically in the marginal valve between every 4 papillae. 


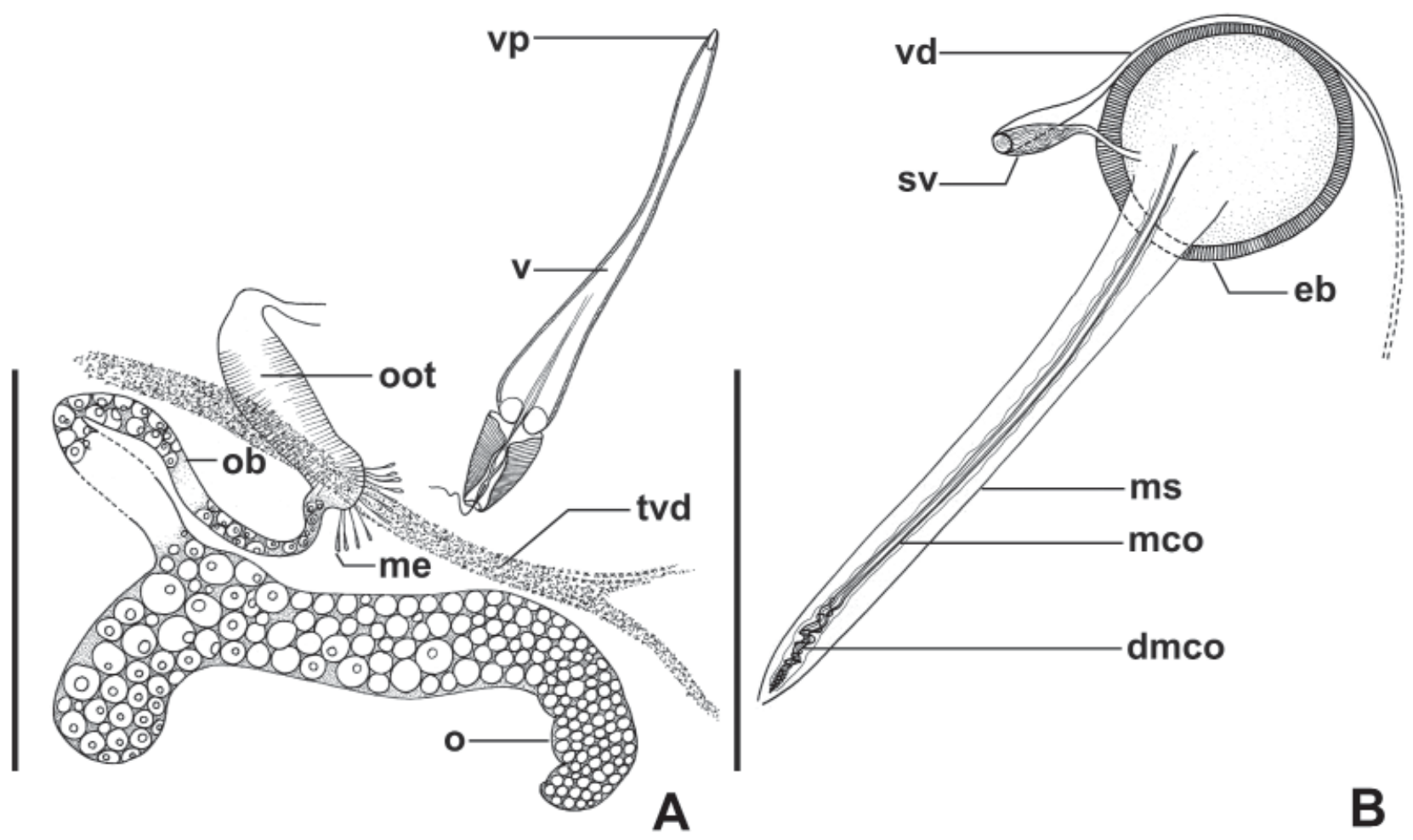

Fig. 3. Dendromonocotyle lotteri sp. n. Reproductive system. A - female reproductive system; B - male reproductive system. Abbreviations as in Fig. 1. me - Mehlis' gland. Scale bars $=500 \mu \mathrm{m}$.
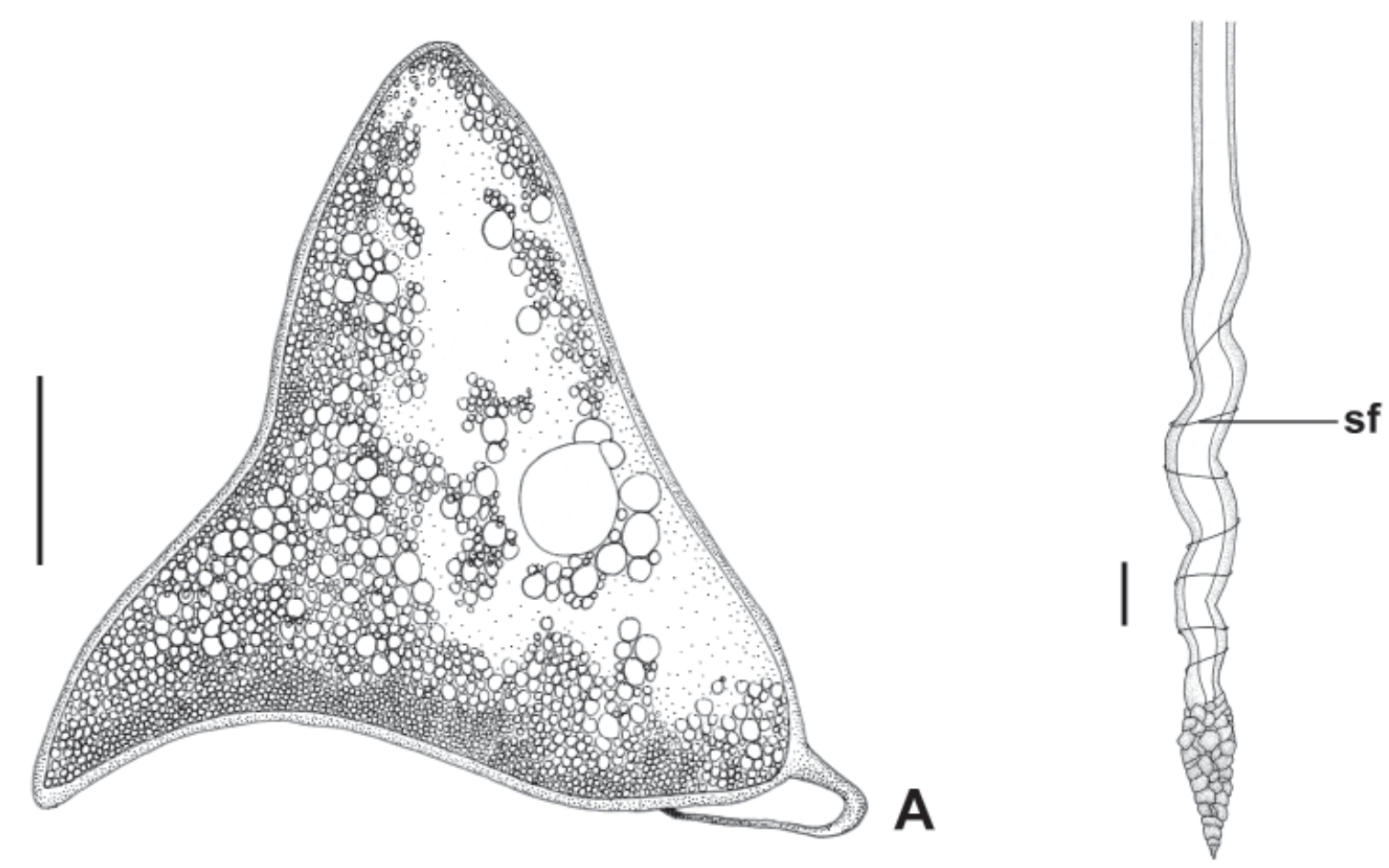

B

Fig. 4. Dendromonocotyle lotteri sp. n. A- egg (inside oötype); B - distal portion of the male copulatory organ showing the sclerotised filament (sf). Scale bars $=20 \mu \mathrm{m}$. 
Vas deferens originates from left side of testis, travels anteriorly, runs towards middle of anterior body section before inflating to form seminal vesicle. Male copulatory organ tightly coiled and folded back on itself, sclerotised, $254 \pm 3.9(252-257, \mathrm{n}=2)$ long, $3 \pm 0.6(3-4, \mathrm{n}=2)$ wide. Distal portion of male copulatory organ tapers to a point; accessory filament absent. Muscular sheath $22 \pm 3.8(19-24, \mathrm{n}=2)$ wide, surrounds entire length of male copulatory organ.

Type host: Neotrygon kuhlii (Müller et Henle) Dasyatidae. Type locality: Moreton Bay, Queensland, Australia.

Additional locality: Burgers' Zoo Aquarium, Arnhem, The Netherlands (host stingrays originally obtained from Jakarta). Site on host: Dorsal skin surface.

Material deposited: SAMCTA 29474 (2 vouchers).

Remarks. Both voucher specimens are juveniles. Three haptoral papillary sclerites are clearly visible on the marginal papillae and not 2 as indicated in the illustration of Young (1967). The male copulatory organ which is straight in adults (see Young 1967, Chisholm and Whittington 1995) is highly coiled in these juvenile specimens. This permits the long male copulatory organ to be accommodated in the smaller body (e.g. Chisholm and Whittington 1995, Chisholm et al. 2001). The male copulatory organ then straightens as the body grows. In addition, the vas deferens in one of the vouchers can clearly be seen originating from the left side of the testis and not from the middle of its anterior-most section as illustrated by Young (1967). This is the first record of $D$. kuhlii from a public aquarium.

\section{Key to Dendromonocotyle species}

1 Male copulatory organ not extending beyond level of posterior portion of ejaculatory bulb

- Male copulatory organ extending beyond level of posterior portion of ejaculatory bulb

3

2 Male copulatory organ with donut-shaped structure midway along length D. centrourae

- Male copulatory organ lacking donut-shaped structure midway along length D. pipinna

3 Haptoral septal pairs 2 and 3 not joining inner ring septum; outer ring septal sclerites absent; hamuli present

D. californica

- All haptoral septa joining inner ring septum; outer ring septal sclerites present; hamuli present or absent

4 Haptor with 38 or 42 marginal papillae .................. 5

- Haptor with 56 marginal papillae ............................ 7

5 Haptor with 38 marginal papillae; spines present at distal end of muscular sheath surrounding male copulatory organ D. lasti
- Haptor with 42 marginal papillae 6

6 Distal end of male copulatory organ looping, accessory filaments present D. ardea

- Distal end of male copulatory organ not looping, accessory filaments absent; vaginal pore armed with spines

D. taeniurae

7 Hamuli present 8

- Hamuli absent .11

8 Inner wall of vagina armed with spines ........................................................ D. ukuthena Inner wall of vagina unarmed .. 9

9 Proximal end of vagina a sclerotised tightly coiled duct; haptoral papillae armed with 3-4 sclerites

D. colorni

- Proximal end of vagina not a sclerotised tightly coiled duct ................................................................. 10

10 Haptoral papillae armed with 7-8 sclerites including terminal papillary sclerite; male copulatory organ not extending to level of ovary D. akajeii

- Haptoral papillae armed with 4-5 sclerites including terminal papillary sclerite; male copulatory organ extends to level of ovary D. lotteri

11 Distal end of male copulatory organ lacking accessory filament 12

- Distal end of male copulatory organ with accessory filament(s)

12 Male copulatory organ with distinct spherical inflation midway along its length ................ D. urogymni

- Male copulatory organ without distinct spherical inflation midway along its length 13

13 Male copulatory organ extending beyond level of ovary; distal end simple tube coming to a point; terminal papillary sclerite keyhole-shaped ...... D. kuhlii - Male copulatory organ extending to level just beyond posterior portion of ejaculatory bulb; distal end widens; ovary anchor-shaped

D. torosa

14 Distal end of male copulatory organ with 2 crisscrossed sperm ducts .......................... D. bradsmithi Distal end of male copulatory with single sperm duct

15 Distal end of sperm duct within male copulatory organ ending subterminally ................... D. octodiscus

- Distal end of sperm duct within male copulatory organ ending terminally ........................................ 16

16 Distal end of sperm duct within male copulatory organ looping once ...................................... D. cortesi - Distal end of sperm duct within male copulatory organ not looping D. citrosa 


\section{DISCUSSION}

There are now 17 known representatives of Dendromonocotyle. Nine of these have been reported from stingrays in captivity including $D$. centrourae Cheung et Whittaker, 1993 from Dasyatis centrourae (Mitchill), D. citrosa Vaughan, Chisholm et Christison, 2008 from Dasyatis chrysonota (Smith) and Himantura gerrardi, D. colorni from Himantura uarnak and H. gerrardi, D. kuhlii from Neotrygon kuhlii, D. lotteri from H. gerrardi, D. octodiscus Hargis, 1955 from Urobatis jamaicensis (Cuvier), D. pipinna Chisholm et Whittington, 2004 from Taeniurops meyeni (Müller et Henle), D. torosa Chisholm et Whittington, 2004 from Aetobatus narinari (Euphrasen) and D. ukuthena Vaughan, Chisholm et Christison, 2008 from $H$. uarnak and $H$. gerrardi. Reports of Dendromonocotyle infections are increasing internationally and some have been responsible for direct skin damage and disease in stingrays kept in captivity. It is likely that the ecology of the captive environment favours the direct life-cycle of these monogeneans. The absence of effective quarantine procedures, host overcrowding/ stress and poor water quality in the exhibit, would certainly play important roles in the onset of sudden population explosions of Dendromonocotyle. Chisholm et al. (2004) indicated that warm water temperature combined with the likelihood of stress in juvenile T. meyeni, caused by interactions with the aquarium patrons at Underwater World, Queensland, Australia, favoured increasing intensities of D. pipinna. Chisholm et al. (2004) found that a proactive approach to their management, by reducing host stress, supported a sustainable equilibrium between host and parasite. Identifying and reducing stressors is paramount, but not always possible. Host stress likely contributed to the problematic infections of Dendromonocotyle species reported by Vaughan et al. (2008) at Sea World at uShaka Marine World in Durban, South Africa. The source of the stress could not be pinpointed, but may have been the combined result of poor water quality, territorial interactions and feeding competition between species in the exhibition. In our opinion the most effective strategy is to actively prevent the introduction of Dendromonocotyle by using adequate preventative quarantine protocols prior to the stingrays being put into the display tanks.

Chisholm et al. (2004) discussed the use of freshwater baths and chemicals to treat Dendromonocotyle infections. However, they noted that when infections are already established in an exhibit, these treatments only give temporary relief because the rays are quickly re-infected by larvae hatching from eggs (which are resistant to treatment), present in the display tank. If the parasite eggs hatch spontaneously, then the simplest method to eliminate infections is to keep the hosts out of the tank until it is determined that all eggs in the system have hatched and the larvae (24 h lifespan on average; see Whittington et al. 2000) have died. However, this strategy will not work if the eggs are waiting for another cue to hatch such as mechanical disturbance or specific chemicals secreted by the host (see Whittington et al. 2000, Chisholm et al. 2004). Furthermore, since we have shown that some Dendromonocotyle species are not strictly host specific, it may not be practical or cost effective to remove all rays from a display tank. Alternatively, treatments can be timed strategically to remove worms from the host after re-infection but prior to the worms reaching maturity and laying more eggs. Thus, after a number of well-timed treatments all eggs could effectively be removed from the system. However, establishing the timing of these treatments is no small feat. Extensive biological data including egg development times, hatching triggers, larval and adult longevity and parasite development time to maturity must be collected at the various temperatures encountered in the display tank.

Dendromonocotyle colorni was originally reported from $H$. uarnak kept in an outside saltwater pond at Israel's Eilat Underwater Observatory (Chisholm et al. 2001). This species is now reported from three different public aquaria from both $H$. uarnak and $H$. gerrardi. Dendromonocotyle octodiscus has also been reported from multiple host species (see Chisholm et al. 2004). Until recently, it was thought that a single ray species was only parasitized by a single species of Dendromonocotyle. However, Vaughan et al. (2008) reported the first sympatric association of three Dendromonocotyle species parasitizing $H$. gerrardi on exhibit at uShaka Sea World. Here we report the second occurrence of a sympatric association between $D$. lotteri and $D$. colorni on $H$. gerrardi kept in captivity. This provides growing support that holding multiple ray species together in captivity may promote opportunistic host-switching in Dendromonocotyle species. There are currently no reports of sympatric associations of Dendromonocotyle species occurring on wild populations of stingrays.

Public aquaria continue to be developed and with the pressures to produce presentable exhibits quickly, the introduction of fishes into new exhibits without the necessary quarantine procedures is becoming more common. This in turn will undoubtedly have an influence on the future occurrence of Dendromonocotyle species on captive stingrays as well as other parasites of aquarium fishes.

Acknowledgements. The authors wish to thank Paul Lötter from the public aquarium at the Atlantis resort for donating the specimens of D. lotteri, and Max Janse from Burgers' Zoo and Dennis Blom for contributing the specimens of D. kuhlii. 


\section{REFERENCES}

Chisholm L.A., Whittington I.D. 1995: A revision of Dendromonocotyle Hargis, 1955 (Monogenea: Monocotylidae) with a description of a new species from Pastinachus sephen (Forsskål) (Myliobatiformes: Dasyatidae) from the Great Barrier Reef, Australia. J. Nat. Hist. 29: 1093-1120.

Chisholm L., Whittington I. 2009: Dendromonocotyle urogymni sp. nov. (Monogenea, Monocotylidae) from Urogymnus asperrimus (Elasmobranchii, Dasyatidae) off eastern Australia. Acta Parasitol. 54: 113-118.

Chisholm L.A., Whittington I.D., Fischer A.B.P. 2004: A review of Dendromonocotyle (Monogenea: Monocotylidae) from the skin of stingrays and their control in public aquaria. Folia Parasitol. 51: 123-130.

Chisholm L.A., Whittington I.D., Kearn G.C. 2001: Dendromonocotyle colorni sp. n. (Monogenea: Monocotylidae) from the skin of Himantura uarnak (Dasyatidae) from Israel and a new

Received 16 March 2009 host record for D. octodiscus Hargis, 1955 from the Bahamas. Folia Parasitol. 48: 15-20.

Compagno L.J.V. 2003: Dasyatidae. In: M.M. Smith and P.C. Heemstra (Eds.), Smiths' Sea Fishes. Third Edition. Struik Publishers, South Africa, pp. 135-142.

Harris P.D., Cable J., Tinsley R.C., Lazarus C.M. 1999: Combined ribosomal DNA and morphological analysis of individual gyrodactylid monogeneans. J. Parasitol. 85: 188-191.

Vaughan D., Chisholm L., Christison K. 2008: Overview of South African Dendromonocotyle (Monogenea: Monocotylidae), with descriptions of 2 new species from stingrays (Dasyatidae) kept in public aquaria. Zootaxa 1826: 26-44.

Whittington I.D., Chisholm L.A., Rohde K. 2000: The larvae of Monogenea (Platyhelminthes). Adv. Parasitol. 44: 139-232.

Young P.C. 1967: A taxonomic revision of the subfamilies Monocotylinae Gamble, 1896 and Dendromonocotylinae Hargis, 1955 (Monogenoidea: Monocotylidae). J. Zool. Lond. 153: 381-422.

Accepted 20 May 2009 